\title{
LA GUERRA CIVIL GUATEMALTECA: HISTORIAS Y MEMORIAS CRUZADAS EN EL ENTORNO GLOBAL DE LA GUERRA FRÍA
}

\author{
Berthold Molden
}

\author{
Recibido: 19/12/2014 Aceptado: 23/05/2015
}

\begin{abstract}
Resumen
Este artículo analiza la historia de la guerra civil de Guatemala, tomando sus conflictos internos armados e intelectuales en contextos centroamericanos, hemisféricos y globales como la base material de la posterior memoria histórica de este periodo, igual de transnacional y también un campo de protagonismo político historizable. Primero, los actores revolucionarios y contrarrevolucionarios son analizados a la luz de sus vínculos transnacionales con redes, entornos discursivos y estrategias de poder que trascienden las fronteras de cada Estado nación y de la región en estudio. Además, la constelación global de la descolonización y la Guerra Fría prestan el trasfondo estructural ante el cual se desarrollaron los actores y las estrategias específicas y contingentes -un contexto amplio de contactos y transferencias que contribuyen a definir las decisiones y alternativas tácticas de cada actor-. Este contexto produjo no solo historias cruzadas, sino también memorias cruzadas. Estas últimas en un doble sentido: por un lado, las historias representadas en las narraciones sobre los antagónicos guatemaltecos y centroamericanos reflejan acontecimientos determinados por constelaciones transnacionales, $y$, por otro lado, estas narraciones en sí mismas han sido construidas en espacios discursivos transnacionales.
\end{abstract}

Palabras clave: Guatemala; Centroamérica; Guerra Fría; historia cruzada; historia intelectual transnacional; memoria histórica.

\begin{abstract}
This essay looks at the history of Guatemala's civil war, its internal armed and intellectual conflicts in their Centralamerican, hemispheric and global contexts, understanding them as the transnational material basis of the equally transnational historical memory of this period, itself a historicizable field of political agency. First, the revolutionary and counterrevolutionary actors are analyzed in the light of their transnational entwinements in networks, discursive environments and power strategies beyond the borders of each nation state and of the region itself. The global constallation of decolonization and the Cold War provides the structural backdrop against which these specific contingent strategies and actors develop, a larger context of contacts and transfers co-defining each actors decisions and range of tactical choices. This context produced not only historias cruzadas, but also memorias cruzadas - in double sense: one the one hand, the histories represented in the narratives about Guatemalan and Central American antagonisms reflect transnationally determined occurences; on the other, these narratives have themselves been constructed in transnational discursive spaces.
\end{abstract}

Key words: Guatemala; Central America; Cold War; histoire croisée; transnational intellectual history; historical memory. 


\section{Introducción}

Como en cualquier parte del mundo, el istmo centroamericano se vio afectado, a lo largo del siglo XX, por choques entre el liberalismo y el conservadurismo, el capitalismo y el marxismo, el elitismo y el igualitarismo, el colonialismo y el anticolonialismo, la revolución y la contrarrevolución. Algunas ideologías, retóricas y prácticas políticas emergieron ahí y se difundieron, mientras otras llegaron de fuera mediante transferencias intelectuales y la creciente globalización de medios, del comercio y de la migración. En este contexto, los imperios coloniales, que durante siglos habían compartido y consolidado el control económico-militar sobre el mundo, debieron retroceder y se establecieron nuevos poderes, cuya pretensión hegemónica de cierto modo resultó incluso más total que los regímenes racistas coloniales.

Aparentemente nadie podía eximirse de esta confrontación bipolar de la llamada Guerra Fría que en realidad incluía una multitud de matices político-ideológicos, lo cual da como resultado un mapa complejo de capas espaciales y diacrónicas sobre el que los actores centroamericanos y extranjeros se movían de manera multidireccional. Se apropiaron de ideas y prácticas políticas, las transformaron y las transfirieron a otras partes, tanto difusores como receptores, a veces perpetradores y en otras víctimas. Durante el proceso de formar sus Estados nación, los países centroamericanos crearon un espacio transnacional entre sí, pero también permaneció una región sumamente penetrable desde sus vecinos americanos hasta el mundo en general. La culminación fatal de los antagonismos sociales e ideológicos fueron los regímenes de terror estatal y las guerras civiles durante la época frívolamente denominada como "Guerra Fría".

Este ensayo pretende, por una parte, interpretar la historia de la Guerra Fría centroamericana, no como una serie de conflictos subsidiarios, ni como resultado de una violencia inherente a un presunto "carácter latinoamericano", del cual "como hijos de Caín [los latinoamericanos son] incapaces... de escapar" (Grandin, 2007: 173); sino más bien entendiéndola como producto de las interacciones continuas, de las cambiantes relaciones de fuerzas transnacionales que reflejan las políticas globales y las pretensiones imperiales de la superpotencia americana, al tiempo que contribuyen elementos endógenos. Por otro lado, no es un estudio de caso profundo donde se entrecruzan historias o memorias específicas, sino un análisis que recorre nudos, cruces y entrelazamientos que se encuentran al estudiar la posición de Centroamérica dentro de las contiendas ideológicas de la "era de los extremos" (Hobsbawm, 1994).

Para capturar estos cruces, se sigue la propuesta de Víctor Hugo Acuña (2015) (ver artículo en este número) de aplicar a Centroamérica el lente teórico-metodológico de la historia cruzada. La historia cruzada fue desarrollada por Michael Werner y Bénédicte Zimmermann como alternativa a otros modelos como la comparación, 
la historia compartida y los estudios de transferencias, o como la combinación de los tres. Hace hincapié en los impactos que el contacto entre actores o entornos históricos deja en todos los que intervienen (Werner et al., 2006).

Acuña propuso usar este mismo concepto para el análisis de la memoria política centroamericana en la introducción a su colección de textos sobre la guerra filibustera de 1856-1857. Según él, "el entrecruzamiento es una especie de yunque o crisol en el cual los fenómenos que por él pasan ya no son los mismos" (Acuña, 2014: 7). Sin usar el concepto explícitamente, el historiador vienés David Mayer (2011) mostró este tipo de correlaciones en su disertación -en curso de publicación- sobre los debates de historiografía marxista latinoamericana: una historia intelectual que no se puede reducir a lógicas de difusión ni de transferencias.

En este ensayo, se aplica el enfoque de Acuña (2015) a la historia y memoria de las guerras civiles centroamericanas. Las redes y los enlaces complejos que se extendieron por la época de las guerras se entienden como base material (de protagonistas, partidos, medios y las retóricas y prácticas usados por y en ellos) de las memorias resultantes -que igualmente fueron inscritas en un entorno no solo regional, sino también global.

\section{La guerra de guerrillas y la contrainsurgencia en sus contextos globales}

A mediados de la década de 1950, América Latina entró a una época de doble calidad transnacional: las luchas revolucionarias y la represión contrarrevolucionaria en su "larga Guerra Fría" (Grandin et al., 2010). Ambos ejes crearon numerosos entrecruzamientos, los cuales siguen siendo objeto de continúas reevaluaciones (Oikión et al., 2014). El golpe a la Revolución guatemalteca en 1954 ha sido considerado un evento de fuertísimo impacto en la historia política e ideológica de América Latina, pues abrió un nuevo marco de acción para la política intervencionista de Estados Unidos. Por lo que fue percibido como eco de tantos casos anteriores de intromisión políticomilitar estadounidense desde el primer auge del liberalismo hasta finales del siglo XIX. Es cierto que había más instancias de continuidad que de ruptura, pero las recientes transformaciones en Costa Rica (1948) y Guatemala (1944) habían indicado la posibilidad de nuevos caminos dentro de un entorno democrático general después de la Segunda Guerra Mundial (Bethell et al., 1992).

Fue un ambiente reformista empujado por las propuestas desarrollistas del cepalismo, en el cual las cambiantes relaciones de fuerzas entre grupos de centroizquierda y derecha, partidos y organizaciones comunistas y los representantes de un conservadurismo radical (sobre todo en defensa del estatus quo en términos de la distribución de la riqueza en cada país), crearon caminos y alianzas diferentes. Por ejemplo, el pacto costarricense entre el calderonismo y el Partido Comunista terminó con un triunfo socialdemócrata-aprista que creó la posibilidad de una doctrina 
económica-política moderada única en la región, la cual pudo coexistir con la política exterior de Estados Unidos gracias a su fiable anticomunismo.

Así, en Guatemala, en el mismo año que Figueres Ferrer llegó a la presidencia constitucional costarricense por primera vez, el gobierno de Jacobo Árbenz que trabajó con los comunistas del Partido Guatemalteco del Trabajo (PGT) y había empezado hace poco su reforma agraria, sufrió la alianza entre los sectores contrarrevolucionarios guatemaltecos, el sector bananero y el Gobierno estadounidense.

Los estrategas de la Guerra Fría en Washington percibieron el "éxito" del golpe guatemalteco contrarrevolucionario en Guatemala como una lección. Cuando, en 1954, el ministro norteamericano de asuntos exteriores, John Foster Dulles, se fijó en Vietnam como la puerta para el sureste de Asia; motivo por el cual el ministro de defensa Charles Wilson advirtió de una aventura "totalmente desesperada" (Rabe, 1990: 176). El hecho de que tanto Eisenhower como los hermanos Dulles desoyeron la advertencia de Wilson fue en gran parte el resultado de una experiencia política "exitosa" en años recientes -la intervención en Guatemala en junio de 1954-.

Sin embargo, el golpe contra el Gobierno reformista de Jacobo Árbenz lo llevó a cabo el coronel guatemalteco Castillo Armas con apoyo de la Agencia Central de Inteligencia (CIA, por sus siglas en inglés), y las tropas estadounidenses. La victoria resultó "barata" para Dulles. Por lo tanto, este explicó al Comité de Relaciones Exteriores del Senado (13 de enero de 1955) la necesidad de entrar a Vietnam, y de intervenir en Guatemala, pues la situación era igual de desesperada, "pero mantuvimos el corazón fuerte, la valentía en alto y entonces, de pronto las cosas empezaron a ir mejor, esto puede ser que suceda en Vietnam" (Herring, 1990: 229-330).

Durante la década de los sesenta, Estados Unidos seguía facilitando ayuda militar para los regímenes contrainsurgentes de América Latina. Por lo que estrategas como el general William Yarborough y John Longan viajaron a Asia y América Latina como asesores e instructores, para transferir las experiencias contrainsurgentes hechas en ambas regiones. Oliver North, quien había sido acusado de crímenes de guerra en Vietman, se transformó en la figura central del escándalo Irán-Contra, formando parte de toda una generación de asesores militares de "seguridad nacional".

El golpe de Suharto en Indonesia en 1965 y la combinación de terror estatal y liberalismo económico del nuevo régimen abrió otro vector de transferencias, dando inspiración importante para el intervencionismo de Estados Unidos en Chile durante la década de 1970 (Easter, 2005). Por otro lado, la experiencia de las masacres de grupos étnicos y religiosos durante la "transición" en Indonesia fue utilizada para la introducir el tema del genocidio en la crítica de la izquierda hacia las políticas anticomunistas de la Guerra Fría (Cribb, 2001). Pasaron años hasta que los métodos represivos en América Central se transformaran de terror selectivo a masacres, pero esto probablemente era inevitable desde el inicio, dada la estructura racista de las sociedades poscoloniales centroamericanas. 
En 1967, Jean-Paul Sartre, como presidente del llamado Tribunal Russell sobre los crímenes de guerra cometidos por Estados Unidos en Vietnam, se refirió a la Guerra Fría global como al marco político de lo que pasó en aquel país. En este tribunal participaron representantes de una izquierda global anticolonial, entre ellos latinoamericanos como Julio Cortázar y Lázaro Cárdenas. Además, Sartre citó al general William Westmoreland, quien había dicho que Estados Unidos se involucró en la guerra en Vietnam "para mostrar que la estrategia de guerra de guerrillas no tiene éxito" (Duffet, 1970: 618), y preguntó retóricamente a quién era dedicada esta demostración, a lo cual respondió que era un asunto de economía y que era concebida como amenaza para América Latina y para todo el Tercer Mundo. El análisis de Sartre fue usual en ese tiempo, en parte porque las "lecciones" históricas de las políticas militares de Estados Unidos en América Latina ya habían sido fundamentales para justificar la intervención en Vietnam y viceversa.

Desde Centroamérica, las guerras y las negociaciones de paz presentaban un entorno regional y global, pues existían muchos enlaces y cruzadas transnacionales entre los movimientos revolucionarios guatemaltecos con otros grupos centroamericanos, por ejemplo con Cuba, con México y, en algunos casos, con Vietnam. Los miembros de diferentes organizaciones de la izquierda latinoamericana (164 líderes de 27 países) se reunieron por primera vez en la Conferencia Tricontinental de 1966, con la famosa intervención del Che Guevara y la fundación de la Organización Latinoamericana de Solidaridad (OLAS), para discutir de forma colectiva las estrategias políticas a implementar (Marchesi, 2009) y, además, fungieron como amplificadoras del internacionalismo anticolonial entre Asia, África y América, incluyendo a los movimientos afroamericanos radicales en Estados Unidos (Bloom et al., 2013; Rodríguez, 2005; Seidmann, 2012).

A partir de 1974 en el Cono Sur operó la Junta de Coordinación Revolucionaria, nacida del afán internacionalista del Movimiento de Izquierda Revolucionaria de Chile (MIR), y respondiendo al mismo llamado de Guevara (refleja un guevarismo independiente de Cuba, véase Löwy, 2007) Al respecto Colussi et al. (s. f.) afirma que

El MIR, y en especial la Dirección encabezada por Miguel [Enríquez], recogieron el llamado estratégico realizado por el Che, a través de la Tricontinental, de realizar coordinaciones revolucionarias en la región. A nuestro juicio, el internacionalismo proletario y una estrategia latinoamericanista sigue siendo un imperativo estratégico para nuestros pueblos, que no se vea arriesgada por algún paso táctico.

En una de sus primeras publicaciones, el MIR menciona sus contactos con organizaciones hermanas en Centroamérica: 
La unidad internacionalista de la vanguardia latinoamericana, razón de ser de la Junta de Coordinación Revolucionaria (JCR), es un elemento estratégico de la lucha liberacionista de los pueblos de nuestro continente [...] Así lo ven distintas organizaciones hermanas del Perú, Venezuela, Guatemala, Brasil, Paraguay, México, Colombia, Nicaragua, Santo Domingo y El Salvador, con las que hemos establecido relaciones con propósitos unitarios

(Junta de Coordinación Revolucionaria, 1975). Desde la otra orilla ideológica, los organizadores, también internacionalistas, de la Operación Cóndor, observaron estas actividades detalladamente (Armony, 2004: 331).

Durante el auge de la exportación revolucionaria, Cuba jugó un papel muy importante al convertirse en un lugar de refugio para exiliados y de entrenamiento para guerrilleros, entre quienes se destacan Marco Antonio Yon Sosa y Luis Augusto Turcios Lima, iniciadores de la lucha guerrillera en Guatemala y exiliados en Cuba, al igual que el expresidente guatemalteco; e incluso se puede mencionar a familias de guerrilleros que se exiliaron en Cuba o en México ante el terror contrainsurgente de los Estados centroamericanos

La Tricontinental, la OLAS y revistas como Pensamiento Crítico fueron de gran importancia al servir de enlaces y plataformas de intercambio y difusión en este periodo. El número 15 de Pensamiento Crítico, en abril de 1968, estuvo dedicado a Guatemala y contenía artículos de Yon Sosa y Turcios Lima. Entre sus lectores y autores figuraba el liderazgo intelectual y militar de la oposición radical centroamericana, como el de Carlos Fonseca, Roque Dalton y muchos otros (Kohan, 2006). Para enfocar el nivel micro de estos vínculos resulta interesante el encuentro entre Fonseca y Turcios Lima en 1959, cuando Fonseca estuvo encarcelado en Guatemala y Turcios Lima era su carcelero. En 1970, Fonseca recordó que el joven soldado guatemalteco de entonces no parecía muy consciente políticamente, "pero escuchaba" (González Bermejo, 1979).

La violencia con que se interrumpieron las luchas laborales y agrarias en la década de 1950 (en Honduras, Guatemala y El Salvador) y la represión ideológica de ese momento contribuyeron al surgimiento de movimientos guerrilleros en la región a partir de 1960 (especialmente en Guatemala, Nicaragua y El Salvador). Los primeros movimientos pronto experimentaron derrotas fatales y muchos insurgentes huyeron al extranjero, sobre todo a México, donde se produjeron contactos con políticos exiliados, sobre todo comunistas. Similar a las primeras décadas del siglo XX, estos exilios y desplazamientos de activistas políticos (y a veces, y cada vez más grandes poblaciones desarraigadas por las guerras civiles) crearon redes regionales que reforzaron los empeños de cada grupo específico, no solo por apoyo logístico o material, sino también para enriquecerlos con sus respectivas experiencias.

Al respecto, Roniger (2013) hace hincapié en que, aunque se formaron diferentes caminos en el desarrollo ideológico-estructural de los regímenes centroamericanos, también se debe subrayar las persistentes conexiones transnacionales, que penetran y 
transcienden las fronteras nacionales antes y durante la Guerra Fría. Además, Roniger (2013) menciona la historia cruzada de los exilios políticos como una esfera idónea para estudiar esta interconexión (como estudio de caso véase Ludec, 2001).

En marzo de 1962, los insurrectos guatemaltecos anunciaron su regreso al escenario político como Movimiento Revolucionario 13 de Noviembre (MR-13). En diciembre de ese año, el MR-13 se unió a otros dos grupos armados bajo el mando general de Marco Antonio Yon Sosa para formar las Fuerzas Armadas Rebeldes (FAR). Esta constituye otra cruzada histórica de transferencias y enseñanzas con resultados aparentemente inesperados, pues tanto Yon Sosa como el otro comandante ícono de esta primera generación guerrillera, Luis Augusto Turcios Lima, eran oficiales del Ejército, $\mathrm{y}$ ambos fueron entrenados en estrategias contrainsurgentes en instituciones estadounidenses de la lucha hemisférica contra el comunismo.

Aunque estuvieron divididos por las líneas de ruptura clásicas de la izquierda de la época (maoísmo, castrismo/guevarismo, comunismo de línea soviética, etc.), ambos compartieron el sentimiento internacionalista del tricontinentalismo, como bien lo dijo Turcios Lima, quien participó en la Conferencia Tricontinental de 1966 en La Habana:

La primera y más importante forma de solidaridad es la lucha misma. Toda acción que se realice, todo golpe que se dé, todo combate que se multiplique contra el imperialismo, es solidaridad efectiva con los demás pueblos de los tres continentes... (Fraga, 2011).

Después de su muerte, en 1966, la Tricontinental publicó parte de la obra escrita de Turcios Lima, incorporándolo, así, al panteón revolucionario del sur global (Fernández, 1970).

Se mantenían contactos entre las organizaciones guerrilleras de Centroamérica y del Cono Sur. Y según los testimonios de líderes guerrilleros guatemaltecos, existían vínculos sobre todo con los sandinistas en Nicaragua y el Ejército Revolucionario del Pueblo de El Salvador (ERP), a partir de la década de 1960, aunque no tan fuertes como las relaciones entre el Frente Sandinista de Liberación Nacional (FSLN) y el Frente Farabundo Martí para la Liberación Nacional (FMLN). Muchos revolucionarios centroamericanos participaron en la ofensiva contra Somoza en 1978 y el triunfo sandinista del siguiente año significó un factor estabilizante importante, tanto para las cuatro guerrillas guatemaltecas (que en 1982 formaron la Unidad Revolucionaria Nacional Guatemalteca, URNG), como para el FMLN (Allison et al., 2014).

Por su parte, Guatemala se convirtió en un ejemplo exitoso de cómo Washington pudo montar una contrarrevolución y un laboratorio, o más bien un campo de entrenamiento, para revolucionarios del Cono Sur. Sin embargo, el foco de las FAR en la Sierra de las Minas al oriente de Guatemala, que se había transformado en un núcleo de esperanza para frenar el avance del anticomunismo represivo en América Latina, 
sufrió derrotas significantes en la segunda mitad de la década de los sesenta, sobre todo en 1968. Este revés en la lucha centroamericana coincidió con la radicalización de muchas izquierdas en América del Sur después de la muerte de Ernesto Guevara y su posterior internacionalización, pero también con la fundación de la OLAS.

Fue en este

momento [...] que el centro de gravedad de la lucha revolucionaria pasaba del norte al sur, de la zona del Caribe (Guatemala, Venezuela, Santo Domingo, Colombia) al "cono sur" (Chile, Argentina, Uruguay): expresaba las tendencias de aquel pasado a la vez que imprimia su marca las tendencias del futuro (Marchesi, 2009: 64).

Tardó una década hasta que la Revolución sandinista colocó a Centroamérica el epicentro del interés internacional tanto revolucionario (Rojas Núñez, 2011: 109-142), como contrarrevolucionario (Armony, 1999 y 2004). Ello coincidió con el ya mencionado cambio estratégico, especialmente por parte de las guerrillas guatemaltecas, hacia la llamada "guerra popular prolongada". Mediante una intensa conexión con la población civil indígena se pretendía crear una conciencia revolucionaria popular.

A partir de este proceso de reorientación, y a consecuencia de los contactos con los grupos católicos que formaron parte de la Acción Católica, en Guatemala surgió el Ejército Guerrillero de los Pobres (EGP), cuya dirección ostentaba Ricardo Ramírez. Fundado en el exilio y apoyado por Cuba, en enero de 1972, el EGP entró por México en la región de la selva del Ixcán, en el norte del país, para prepararse militarmente y ganarle a la población de las provincias del Quiché y Huehuetenango. En virtud de las experiencias del fracaso de los años sesenta, el EGP dirigió su atención al campesinado indígena.

Además, el grupo fundador de la Organización del Pueblo en Armas (ORPA) fue disidente de la FARC, que bajo el mando de Rodrigo Asturias, tenía su campo de acción en los departamentos de San Marcos, Sololá, Quetzaltenango y Chimaltenango. Los fundadores de la ORPA se habían confrontado con el debate identitario de los años sesenta y setenta, al concederle al movimiento indígena un papel central en su estrategia, sobre todo a nivel socioeconómico y apenas a nivel cultural. Este aspecto se convirtió, también, en un punto importante en el desarrollo del EGP.

Durante los años setenta, la conexión entre en los cuatro grupos clandestinos -PGT, FAR, EGP y ORPA- y los llamados movimientos de masas jugó un papel importante, ya que se creó una nueva doctrina de lucha popular. Cuando, a partir de 1974, se produjo una rápida y fuerte reactivación de las organizaciones sociales tanto de orientación sindical como de pequeños campesinos indígenas, los grupos guerrilleros se aproximaron a ellas para coordinar la estrategia y ampliar sus propias bases sociales. El Comité de Unidad Campesina (CUC) tuvo un papel de especial importancia en este proceso, pues logró mobilizar la mayor cantidad de campesinos indígenas para 
luchas laborales y sociales. Así, Rigoberta Menchú estableció la relación de cercanía con el EGP, a través de la cual, entre otros factores, alcanzaría más tarde su notoriedad internacional. A finales de los años setenta, el EGP consiguió un asombroso arraigo en la población, tanto civil -a través de los Comités Clandestinos Locales-, como paramilitar - por medio de las Fuerzas Irregulares Locales.

Es interesante exponer esta experiencia guerrillera a una mirada crítica hacia la guerrilla como la del sociólogo francés Yvon Le Bot; quien, en su estudio sobre el enfrentamiento armado interno - de carácter crítico respecto a la guerrilla-, señala que el descubrimiento de la población maya de aquel grupo supuso un desarrollo ambivalente. La dirección del EGP y de la ORPA estaba en manos de ladinos que combinaron el "mesianismo guevariano" (Le Bot, 1997:132) de la revolución comunista, con la doctrina social de la Teología de la Liberación para aliarse a la población maya.

La situación de los mayas, marcada por la explotación, la ausencia de derechos políticos y la pobreza, hizo que esta alianza pareciera inevitable. Sin embargo, para la guerrilla, el potencial revolucionario de la población campesina debía ser remodelado, pues "El ideal campesino no es político en sí mismo, y hay que inculcarle esta cualidad desde fuera" (Le Bot, 1997: 127). Le Bot concluyó que la integración en un proyecto revolucionario "cuyos modelos (Cuba, Vietnam, Nicaragua...) no tenían nada que ver con la historia y la cultura mayas" los habría llevado al siguiente juicio histórico: “Esta guerra no es la nuestra" (Le Bot, 1997: 293-294). Si bien absolvió a la guerrilla de la responsabilidad de haber emprendido una guerra contra los mayas, planteó: "No supo evitar que esta guerra, que consideraba 'necesaria' y que pretendía ser de liberación, se volviera la peor de las guerras contra los mayas, desde la Conquista” (Le Bot, 1997: 296).

El anticomunismo, así como su adversario, fue una ideología que contó con instituciones internacionales (gubernamentales) y transnacionales (religiosas, socioculturales, etc.) (Van Dongen, 2014). La Liga Anticomunista Mundial o Confederación Anticomunista Mundial fue fundada en 1966 en Asia, pero pronto asumió un papel coordinador a nivel transnacional en América Latina, y en 1972 se fundó, en México, la Confederación Anticomunista Latinoamericana (CAL). Esta fue la organización coordinadora central para la colaboración anticomunista del continente, sobre todo en su asistencia para realizar la Operación Cóndor (Mcsherry, 2009). Esta cooperación de terror y opresión se organizó en las conferencias en Paraguay (1977) y Argentina (1980). A esta última asistieron líderes de escuadrones de la muerte de Centroamérica, tan distinguidos como Roberto D'Aubuisson de El Salvador y Mario Sandoval Alarcón de Guatemala (Armony, 2004). El dictador nicaragüense Somoza, menos de un mes antes de ser asesinado en Paraguay, también tuvo ahí sus representantes en caso que se presentara una posibilidad de recuperar el poder (Martorell, 1999).

Por otra parte, se conoce el rol que los gobiernos de Estados Unidos e Israel jugaron en la escalada de la Guerra “Fría” en Centroamérica, pero el involucramiento de países latinoamericanos se ha estudiado menos. Sin embargo, como lo demuestra 
claramente Armony, el anticomunismo transnacional latinoamericano incluyó a Centroamérica. Su mayor exportador fue Argentina durante la última dictadura militar, al querer establecerse como aliado, y ya no solo como auxiliar de Estados Unidos. Así, la Nicaragua sandinista y, en segundo plano, Guatemala y El Salvador, fueron percibidas como campos de batalla de una lucha global. La interacción con gobiernos y con organizaciones paramilitares creó otro espacio transnacional dentro del cual tanto la práctica contrainsurgente como la ideología anticomunista fueron objetos de intercambio (Armony, 1999).

\section{La Teología de la Liberación y su impacto en el proceso de paz centroamericano}

La historia de la Teología de la Liberación es considerada como un macro ejemplar; pues, como es bien conocido, hasta la década de 1950 la cúpula de la jerarquía católica de Centroamérica defendía una ideología conservadora radical, agitando contrarreformas sociales y agrarias, y manteniendo alianzas con oligarquías económicas y regímenes militares. Por lo tanto, resulta irónico que apoyara regímenes liberales, aunque esta actitud tenía parte de su motivación en la mala memoria del fervor anticlerical de las reformas liberales del siglo XIX. Sin embargo, a partir de 1945, la misión pastoral y acción social de la Iglesia frente al protestantismo y al comunismo -manifestadas en la Acción Católica y el catecismo laico- tuvo otra vuelta irónica.

La iniciativa vaticana para una restauración conservadora de la fe católica tomó un giro inesperado cuando algunos misioneros, sorprendidos por la injusticia social, se comprometieron a articular los intereses de los pobres. Este debate en la jerarquía empezó durante del Congreso Eucarístico Internacional y la primera Conferencia General del Episcopado Latinoamericano de 1955 en Río de Janeiro, siguió en Roma durante el Segundo Vaticano y culminó en la Segunda Conferencia General del Episcopado Latinoamericano de 1968 en Medellín, donde se declaró: “Debemos agudizar la conciencia del deber de solidaridad con los pobres, a que la caridad nos lleva. Esta solidaridad significa hacer nuestros sus problemas y sus luchas, saber hablar por ellos" (Segunda Conferencia General del Episcopado Latinoamericano, 1968: 10).

El escenario general de Centroamérica tomó su forma dentro de este contexto continental y global; pues en toda la región emergieron las Comunidades Eclesiales de Base (CEB) como reacción cristiana a las contradicciones sociales. Fueron específicamente fuertes en Nicaragua y El Salvador; en este último también coincidieron con programas de incidencia social de la Iglesia católica, del Partido Demócrata Cristiano y de la Agencia de los Estados Unidos para el Desarrollo Internacional (USAID, por sus siglas en inglés) dentro del contexto de la Alianza para el Progreso, inaugurada por J. F. Kennedy. En esta época gozaron del aval del papa Pablo VI, quien escribió que en las CEB se reunían "personas éstas que la vida misma encuentra ya unidas en la lucha 
por la justicia, la ayuda fraterna a los pobres, la promoción humana, etc." (Pablo VI, 1975). Sin embargo, las cúpulas jerárquicas de la Iglesia en ambos países guardaron una posición más cauta, apoyada desde hace varios años.

Óscar Arnulfo Romero en El Salvador se volvió más explícito en su crítica, y en 1977, ante la agresión masiva de la Unión Guerrera Blanca y el asesinato de amigos suyos jesuitas, hizo una gran crítica que, Roberto D'Aubuisson, uno de los más feroces internacionalistas del terror anticomunista en Centroamérica, aseguró su asesinato en 1980. En ese mismo año, D'Aubuisson participó en la cuarta conferencia de la Confederación Anticomunista Latinoamericana en Buenos Aires.

Por otro lado, en Nicaragua, a pesar de la colaboración de la alta jerarquía católica con el Somocismo, el Movimiento Cristiano Revolucionario y otros grupos nicaragüenses procuraron que Ernesto Cardenal y otros formaran parte del gobierno revolucionario al triunfar el Sandinismo en 1979 (Sawchuk, 1997). Es legendaria la confrontación ocurrida en 1983 entre el jesuita Fernando Cardenal y el papa Juan Pablo II, durante su visita a Nicaragua. El anticomunismo de Juan Pablo II acabó con toda trayectoria vaticana de liberación heredada de la época de Pablo VI.

En Guatemala, después del rol crucial del arzobispo Mariano Rosell Arellano en la contrarrevolución de 1954, sectores de la Iglesia católica también se distanciaron del régimen y fueron duramente perseguidos. A partir, sobre todo de las campañas de tierra arrasada por el Ejército a finales de los años setenta, el compromiso de muchos curas y catequistas aumentó. Uno de ellos fue el jesuita y antropólogo Ricardo Falla, cuya experiencia con las Comunidades de Población en Resistencia en el departamento del Quiché, fue la base de algunos de los primeros libros sobre el genocidio del gobierno militar contra la población maya, publicados tanto en Guatemala como a nivel internacional (Falla, 1978 y 1983).

La derecha militar guatemalteca todavía le guarda rencor y lo identifica como un "cura guerrillero durante el tiempo que militó en el EGP. Él y otro cura guerrillero... son responsables de haber involucrado a numerosos indígenas del Quiché e Ixcán, en las actividades terroristas" (Fundación Contra el Terrorismo, 2013a). Este fue un discurso que negó cualquier protagonismo social a la población indígena (al culpar al comunismo internacional como el demonio seductor) y, al mismo tiempo, planteó que esta formaba parte del "terrorismo"; pero sobre todo enfatizaba que el alegato del genocidio era parte de una conspiración internacional, en este caso una "conspiración Marxista desde la Iglesia Católica" (Fundación Contra el Terrorismo, 2013b). ${ }^{1}$ Esta hostilidad también tuvo su dimensión internacional con la persecución de católicos por los regímenes anticomunistas, como es el caso de la Iglesia Guatemalteca en el Exilio (IGE), que basada en Managua, después de la victoria sandinista, fungió como plataforma importante de movilización internacional. La IGE se solidarizó con "el pueblo sufrido de Guatemala, las organizaciones de masas, los grupos políticos no responsables del terror ni alineados con los opresores... los indígenas que siempre han sido 
víctimas y que hoy son protagonistas en la lucha y en la esperanza" (Iglesia Guatemalteca en el Exilio, 1982). Destaca esta atribución de agencia política a los pueblos mayas -muy diferente a la visión de los gobiernos militares y sus herederos ideológicos-, aunque también se vinculó con la lucha guerrillera.

En el mismo comunicado la IGE enfatizó: "A la solidaridad internacional les pedimos que le den publicidad a este documento de transcendental importancia. Que lo traduzcan en sus lenguas y le den la mayor difusión. Que pidan adhesiones a nivel eclesial, político y popular" (Iglesia Guatemalteca en el Exilio, 1982). Uno de los fuertes de la IGE era su acceso a sectores católicos (y cristianos en general) progresistas en Europa y Estados Unidos, cuyas campañas de opinión pública constituyeron un elemento crucial de la movilización política internacional en contra de las dictaduras centroamericanas y las políticas intervencionistas de Estados Unidos.

Siguiendo el ejemplo de los grupos de solidaridad con Augusto César Sandino en los años veinte $y$, recientemente, de solidaridad con Chile, se formaron redes de solidaridad con Nicaragua y después con Guatemala y El Salvador. Entre los miles de comités y organizaciones fundadas a partir de la década de los setenta, figuraron el Guatemala News and Information Bureau (1978, San Francisco, California), el Network in Solidarity with the People of Guatemala (1981, Oakland, California), la Nicaragua Solidarity Campaign (1978, Inglaterra), el Maritime Guatemala Solidarity Network (1983, Canadá), la Fundación Solidaridad Internacional (1986, formada por organizaciones ya existentes, España), el Guatemala Solidarity Network (1980s, Inglaterra), Informationsbüro Nicaragua (1978, formada por organizaciones ya existentes, Alemania), la Guatemala Initiative / Solidarität (1981, Austria), el Collectif Guatemala (1976/79, Francia).

Muchos protagonistas de la centro-izquierda europea y estadounidense -periodistas, académicos, políticos, activistas- provienen de este ambiente político de los años setenta y ochenta cuya relevancia y trayectoria histórica solo ha comenzado a ser estudiada.

La organización francesa Collectif Guatemala es un buen ejemplo del impacto que tuvo el exilio de izquierda en la movilización pública extranjera. Fundada en 1976 por los guatemaltecos exiliados Miguel Ángel Sandoval y Arturo Taracena, este comité pronto se estableció como uno de los grupos más activos de Europa y preparó el terreno para otras actividades del exilio guatemalteco que luego tuvieron un gran impacto en Guatemala (Taracena, 2005).

Taracena (2005), luego nominado representante del EGP en Francia y de la URNG en Europa, fue corresponsable de la introducción de Rigoberta Menchú a un público internacional, lo cual indica la cercanía de estos grupos con la lucha indígena campesina representada por el Comité de Unidad Campesina (CUC). Otra vez, pues, aparece en este cruce de interconexiones los tres elementos principales en la transnacionalización revolucionaria (y, por extensión, solidaria): cristianismo de liberación, movilización indígena campesina y marxismo revolucionario. 
Sin embargo, en Guatemala, donde la represión contra el presunto comunismo católico provocó que el obispo de El Quiché, Juan Gerardi, se retirara y apartara a casi todos los sacerdotes del departamento, para salvar la vida no solo del clero, sino también de los líderes laicos. Resulta cínico que fue precisamente en la cabecera departamental, Santa Cruz del Quiché, donde el presidente Álvaro Arzú, con el Ejército a su lado, llevó a cabo su gran acto del "perdón nacional", con el cual, en 1998, quería prevenir el impacto del informe inminente de la Comisión de Esclarecimiento Histórico (CEH) (Molden, 2014).

El rol de Juan Gerardi, junto al papel del obispo y posteriormente cardenal Rodolfo Quezada Toruño, permite analizar la interdependencia transnacional del entorno regional y global con el protagonismo nacional. En torno al primero se trata sobre todo del Proceso de Paz Centroamericano, iniciado en 1983 por el Grupo de Contadora (México, Colombia, Panamá y Venezuela), y revitalizado por el proceso de Esquipulas, e impulsado por el expresidente costarricense Óscar Árias (1986-1990) -en desafío a la presión de Reagan- y el primer presidente civil guatemalteco, Vinicio Cerezo (19861991), desde la contrarrevolución (con la excepción de Méndez Montenegro, 1966-1970).

El Proceso de Paz Centroamericano ha sido evaluado como un proceso de intensas negociaciones a nivel nacional e internacional, inscrito en las lógicas pertinentes del fin de la Guerra Fría global. Fueron procesos co-determinados intensamente por actores externos (los países de Contadora, los "países amigos", la Organización de las Naciones Unidas (ONU), y la llamada "comunidad internacional" en general) (Regalado, 2013). Este proceso resultó en el famoso Acuerdo de Esquipulas II, el cual, entre otros pasos, estipula la creación de comisiones nacionales de reconciliación que estarían integradas por "un delegado propietario y un suplente del Poder Ejecutivo, un titular y un suplente sugerido por la Conferencia Episcopal y escogido por el Gobierno de una terna de Obispos" (Acuerdo de Esquipulas II. Procedimiento para establecer la paz firme y duradera en Centroamérica. Guatemala, 7 de agosto de 1987. § 1. C.); con lo cual se confirmó el papel mediador de la Iglesia.

El acuerdo instaló a la Iglesia como un elemento fijo en las comisiones de reconciliación nacional. En Guatemala, los dos obispos, Quezada Toruño y Gerardi, son un ejemplo claro de cómo se manifestó el pensamiento cristiano de reconciliación en el proceso político concreto. La Conferencia Episcopal de Guatemala, presidida por Quezada Toruño, nominó a Gerardi y al mismo Quezada Toruño para la Comisión de Reconciliación Nacional (CRN). Gerardi estuvo exiliado en Costa Rica en los años ochenta, mientras que Quezada Toruño fue obispo en el departamento, relativamente tranquilo, de Zacapa (donde no hubo genocidio porque casi no había población maya). Él también asumió la presidencia de la Comisión hasta 1993 y fue conciliador oficial en el proceso de negociación entre el Ejército y la guerrilla -una posición similar a la que después tuvo el mediador de la ONU Jean Arnault-. Resulta interesante que Quezada Toruño aceptó esta función en 
Oslo por un periodo de cuatro años (1990-1994), cuando, también en Oslo, se firmó el acuerdo sobre la Comisión de la Verdad.

Resulta interesante que entre los dos "obispos de la paz" fue Juan Gerardi, quien se entregó de lleno a la búsqueda de la verdad (una meta empujada desde la comunidad internacional), más que la reconciliación (un fin determinado sobre todo por los países mismos en camino de transición pactada hacia la democracia). Gerardi dirigió la Oficina de Derechos Humanos del Arzobispado de Guatemala que fue fundado en 1990. Ahí, asistido por el sociólogo crítico Edgar Gutiérrez, inició el proyecto de Recuperación de la Memoria Histórica (REMHI), el cual consistió en acusar al Estado y al Ejército de violaciones sistemáticas de los derechos humanos, así como de actos de genocidio. Es decir, mientras Quezada Toruño incorporó la figura conciliadora y curativa que profundizó el "diálogo nacional”, Gerardi -si bien admirado por muchos como "mártir de la verdad" después de su asesinato- provocó a poderosos sectores como el reverso de su colega.

De hecho, el informe del REMHI “Guatemala Nunca Más” insistió en que la transformación moral en la historia de Guatemala tenía que ser precedida por un reconocimiento general de culpa y responsabilidad de todas las partes, pero no solo de la guerrilla y del Ejército (ODHA, 1998). Tal visión, no dualista del conflicto, incluyó al sector privado y también a la Iglesia católica, socavando cualquier noción simplista de reconciliación. Cuando una corte civil condenó, por primera vez, a dos oficiales y a un soldado, junto a un sacerdote, por el asesinato de Gerardi, el sector militar reaccionó con indignación.

Así, fue en septiembre del 2001, medio año después de las condenas substanciales, cuando la Asociación de Veteranos Militares de Guatemala (AVEMILGUA) organizó un debate público en donde se lamentó la "justicia política" y la depreciación del Ejército. En su comentario final, el general Víctor Manuel Argueta Villalta, entonces presidente de la asociación, condicionó la disposición reconciliadora del Ejército con una sentencia favorable de la Corte Suprema de Justicia (Argueta Villalta, 2002). Sin embargo, no fue ninguna sorpresa que cualquier sospecha contra las fuerzas armadas fuera descartada como una conspiración por los excolaboradores católicos de la guerrilla, quienes supuestamente habían secuestrado a las comisiones de la verdad y ahora tergiversaban la historia (Murga, 2001).

\section{Del proceso de paz al enfrentamiento mnemónico interno}

No es casual que en ese momento surjan las comisiones de la verdad. El recorrido de nudos y entrecruzamientos en la historia de los antagonismos en Centroamérica lleva a la época de la representación a posteriori de esta historia. En especial porque las causas político-históricas de los enfrentamientos armados no han sido removidas y tampoco han desaparecido los conflictos ideológicos sobre ellas. Además de 
eso, se debe agregar un nuevo enfrentamiento en la memoria de las luchas utópicas y represivas de Centroamérica.

Entre estos entrecruzamientos destacan las estructuras transnacionales formadas por las organizaciones de derechos humanos. Diversas plataformas de la sociedad civil articularon las posiciones de organizaciones populares y diferentes sectores, y también visibilizaron las diferencias irreconciliables entre algunos de ellos. El sector privado agroindustrial y empresarial en muchas ocasiones no quiso colaborar con organizaciones populares. Eso se demostró cuando, en 1995, el proceso de paz guatemalteco experimentó cambios en dos dimensiones fundamentales: el rol de la "sociedad civil" y de la "comunidad internacional", los cuales fueron institucionalizados al mismo tiempo.

Así mismo, se creó la Asamblea de la Sociedad Civil (ASC) como plataforma para la participación de actores de la sociedad civil. Mientras que el Ejército y el Gobierno se veían obligados a tomar parte en las negociaciones, y la URNG las concebía como medio político de su estrategia (Rosada-Granados, 1998); así, el proceso abrió para las organizaciones de la sociedad civil una plataforma de acción política que le había estado vedada en las estructuras políticas tradicionales. En las siguientes rondas de negociaciones, la ASC tuvo una participación activa, aunque no estaba representada en la mesa de negociación y sus ideas no quedaron siempre representadas a su satisfacción en los acuerdos finalmente negociados. Esta situación contradictoria -frustración en el campo de negociaciones institucionales, pero gran impacto sobre el discurso público- se hizo patente, sobre todo, en las protestas contra el carácter otorgado a la futura comisión de esclarecimiento y un año más tarde, con motivo del "Acuerdo sobre identidad y derechos de los pueblos indígenas". Aunque, técnicamente formaba parte de la sociedad civil el Comité Coordinador de Asociaciones Agrícolas, Comerciales, Industriales y Financieras (CACIF) se negó a participar en la ASC porque “dada la forma de su estructura y organización nosotros habíamos decidido no participar en ella y canalizar nuestras opiniones sobre la negociación directamente" (Carta del CACIF a Boutros Boutros Ghali, 13 de enero de 1995). En esta carta al secretario general, el CACIF acusó a la URNG de dominar el discurso de la sociedad civil.

La segunda innovación central de 1995 fue el papel de mediador asumido por Jean Arnault en nombre de la ONU que en principio chocó, una vez más, contra un fuerte rechazo del Ejército y del CACIF, fue llevada adelante mediante la insistencia de la comunidad internacional y de la URNG. Además, el llamado "Grupo de Amigos", en el que estaban representados México, España, Noruega y los Estados Unidos, así como Venezuela y Colombia, desempeñó un papel importante. Sin embargo, ante la poco entusiasta dinámica de la negociación del gobierno de León Carpio, el compromiso directo de la comunidad internacional resultó decisivo para el proceso de paz. En marzo y en junio de 1994 se firmaron tres acuerdos sustanciales: el Acuerdo global 
sobre derechos humanos (en marzo), el Acuerdo para el reasentamiento de las poblaciones desarraigadas y -después de difíciles negociaciones que pusieron en evidencia el miedo del gobierno, el Ejército y el CACIF, ante investigaciones independientes (es decir, de la guerrilla) de la historia más reciente-, y el Acuerdo sobre el establecimiento de la Comisión para el Esclarecimiento Histórico (CEH).

El acuerdo sobre los derechos humanos suponía la culminación de las disposiciones generales del pacto sobre la democratización de julio de 1991, pero iba mucho más allá de lo entonces previsto, pues ahora -lo que para el presente trabajo resulta de importancia- no solo se establecían las prestaciones de resarcimiento por violaciones de derechos humanos como una obligación estatal, sino también la creación de una Misión de Naciones Unidas en Guatemala (MINUGUA) en territorio guatemalteco.

Había sido especialmente difícil llevar adelante una misión como esta frente al Ejército y a la representación de los empresarios, por ello solo pudo iniciar su trabajo en noviembre de 1994. Con la atención de la comunidad internacional-que a partir de 1995 presionó cada vez más a los grupos escépticos ante las negociaciones de las que formaba parte el gobierno y el CACIF-, MINUGUA tuvo un efecto positivo sobre la situación de los derechos humanos. Sobre todo en el primero de sus informes de control, que aparecían varias veces al año y a veces se dedicaban a áreas temáticas seleccionadas; por lo que la misión destacó la importancia central de la impunidad -y, con ello, la responsabilidad implícita del Estado- para la todavía alta cifra de casos de violaciones de derechos humanos. A causa de sus claros posicionamientos -por ejemplo, con motivo de una de las últimas masacres del conflicto armado interno en 1995, en la comunidad de retornados/ y retornadas de Xamán-, MINUGUA entró en conflicto con el Ejército y el gobierno hasta el final de sus diez años de trabajo, a finales de 2004.

\section{"Externalización" como estrategia defensiva en las políticas de la memoria}

La estrategia de externalizar responsabilidades históricas -es decir, culpar únicamente a fuerzas externas de actos cometidos por actores locales- es clásica en todas las sociedades, y en América Latina son famosas sus variaciones de los "dos demonios", los "dos fuegos" y del "sándwich". Se habló en términos de la violencia política de un escenario global presuntamente inescapable que no permitió otro camino más que la violencia a cada país, y en este caso las superpotencias eran mayormente responsables de las guerras internas. Ello no solo indica la conciencia que los actores nacionales tienen del enlazamiento estructural global, sino sobre todo de modos del escapismo histórico-político.

En el Ejército, la interpretación histórica institucionalmente desarrollada fuela de la defensa de las soberanías nacionales contra la conspiración internacional comunista. Esta versión viene equipada con una pequeña genealogía ideológico-intelectual de la izquierda como una errata trágica de cualquier otra perspectiva gloriosa de la historia de ideas de Europa. De unas docenas de páginas a modo de doctrina, presenta una línea inescapable desde las primeras críticas marxistas del siglo XIX y los presuntos 
llamados "vende patrias" de las guerrillas del periodo 1960-1990. En esta historia, el Ejército es el defensor de la soberanía nacional, por lo tanto no sorprende encontrar un ejemplo clásico de este discurso precisamente en la intervención histórico-política más masiva que AVEMILGUA empeñó en las luchas por la hegemonía en la representación histórica (AVEMILGUA, 1998).

Originalmente, se aceptó también su rol en una lucha global contra el comunismo, pero muchas veces los ejércitos asumieron una vieja tradición nacionalista ante el retiro parcial de Washington durante la administración de Carter. La amplia existencia transnacional de tales "discursos de manual" indica que fue difundido por diversos mecanismos, como la Escuela de las Américas y otras redes contrarrevolucionarias de intercambio y entrenamiento mutuo.

Como resumen de una narrativa que resultó muy común entre representantes tanto del sector privado como del Ejército, se puede mencionar las palabras del empresario y comentarista Humberto Pretti, con las cuales explica su visión del origen de la guerrilla:

Mire, el conflicto armado hay que situarlo perfectamente en donde estuvo su inicio. Su inicio fue en el tiempo de Ydigoras Fuentes cuando los espacios politicos estaban totalmente cerrados. Tanto es así que [...] el Movimiento del 13 de Noviembre en el año 1962 [... primero fue] a buscar [...] a los americanos. No fue una cuestión ideológica de decir "vamos a ir a buscar a los cubanos o a los rusos para comenzar una guerra ideológica por principios marxistas". ¡No! Ellos primero buscaron a los americanos. Turcios Lima y Yon Sosa, ellos primero buscaron el apoyo de los Estados Unidos para ver si Estados Unidos ayudaba a que hubiera más oportunidades políticas porque aquí todo estaba cerrado prácticamente. No había posibilidades de que alguien más inscribiera un partido. Y el que decía que era de izquierda o el que se opusiera al gobierno, sencillamente era purgado o sencillamente no existía el partido, no se lo inscribian. Cuando los americanos les dicen que no, nosotros no podemos romper la institucionalidad. Pues Yon Sosa se va a la China y Turcios Lima se va a la Cuba. El chino Yon Sosa como era chino se va a la China a obtener apoyo y el otro se fue con Fidel y con los rusos. De ahi se inicia el conflicto armado. Así fue (Entrevista del autor con Huberto Pretti, 22 de abril 2003). ${ }^{2}$

Sin embargo, no solamente se trata de ubicar a nivel internacional las fuerzas determinantes para los acontecimientos guatemaltecos, sino también de la adscripción general de la "culpa histórica" a actores externos. De este modo, en 1999, el entonces ministro de la Defensa guatemalteco, Héctor Barrios Celada, se quejó porque "los intereses hegemónicos fueron otro factor que permitió el conflicto y en cierta forma, no nos han dejado desarrollarnos o vivir en paz que es lo que pedimos ahora, que nadie meta las manos en nuestro país" (Barrios Celada, 1999).

Desde las negociaciones de paz hasta el acompañamiento internacional durante la posguerra, siempre ha habido críticas contra la diplomacia internacional como intervencionista y encima de todo insensible hacia las correlaciones sociales guatemaltecas. 
La intensa colaboración entre organizaciones centroamericanas y otras organizaciones europeas y americanas, y cierta influencia sobre posiciones gubernamentales en el extranjero no fue vista, por el Ejército ni el sector privado, como un laudable momento de entrecruzamiento histórico-político; pues para ellos era una conspiración diplomática izquierdista al no poder triunfar en el plano militar.

Ante esto, se debe uno recordar uno de los momentos más simbólicos en esos procesos simultáneos de negociación diplomática y lucha por la memoria: el Premio Nobel de la Paz para Rigoberta Menchú Tum en 1992. Al respecto, cabe destacar el comentario de la intelectual Maya Irma Alicia Velázquez Nimatuj, quien en 1992 trabajó como periodista en el diario guatemalteco Prensa Libre:

Y recuerdo que el director de Prensa Libre este día cuando ganó Rigoberta entró a la sala de sesiones y dijo que no podía creer lo que habian hecho con el país, que ahora todo el mundo iba a saber que somos un país de indios. Y que eso habia hecho mucho daño. Que los señores que habian dado el Premio Novel a Rigoberta no entendian [lo que] eso implicaba para Guatemala. Y recuerdo que en esta mesa de reunión yo fui la única persona que le dijo que yo no estaba de acuerdo con esta opinión (Entrevista del autor con Irma Alicia Velázquez Nimatuj, 26 de abril de 2002).

A pesar de tal rechazo sectorial en Guatemala, su historia nacional había contribuido a cambiar el ambiente global, pues Menchú representó una lucha antineocolonial de 500 años. El trabajo público internacional organizado en conjunto con organizaciones revolucionarias armadas y civiles (en este caso sobre todo el CUC y el EGP) resultó en un reconocimiento transversal de varias luchas representadas en una activista Maya guatemalteca: la indígena americana (poscolonial), la de los pobres (de clase) y la de la mujer (género), encarnadas simultáneamente en Menchú. Al declarar en su famoso testimonio la experiencia de "todos los guatemaltecos pobres", ella asumió una voz colectiva que trascendió incluso a los campesinos pobres de Guatemala y soñó con la solidaridad que auto empodere, con la subalternidad transnacional, y soñó como eco del tricontinentalismo.

En 1999, en un momento preciso como para deslegitimar el inminente informe de la comisión internacional de la verdad, surgió la gran controversia sobre la veracidad de la historia de Menchú, situación que fue iniciada por la crítica del antropólogo estadounidense David Stoll. Stoll se había empeñado en refutar una serie de detalles en el relato de Menchú como ejemplo para la supuesta tergiversación histórica por parte de las guerrillas latinoamericanas y la izquierda académica estadounidense. A partir de esto, los diferentes debates histórico-políticos desencadenados en Guatemala y Estados Unidos, constituyen un momento clásico de entrecruzamiento histórico. En este caso no solo se cruzaron actores cuyos intereses se jugaron en diferentes países con sus enfrentamientos culturales nacionales, sino también provenientes de diversos espacios de acción social: académicos e intelectuales públicos en ambos países con 
actores políticos en Guatemala; quienes, en sus articulaciones, influyeron los unos en los otros. Así, las luchas reales guatemaltecas se controvirtieron en moneda discursiva en los "Culture Wars" estadounidenses, mientras en Guatemala las proclamaciones de profesores extranjeros llegaron a codeterminar el debate político interétnico.

Otro eje transnacional-global vinculado con las relaciones étnicas de Centroamérica también vino articulándose por lo menos desde los años chenta en torno al discurso del genocidio. Desde las campañas públicas del Grupo de Apoyo Mutuo (GAM), la Coordinadora Nacional de Viudas de Guatemala (CONAVIGUA), la Iglesia Guatemalteca en el Exilio (IGE) y otras organizaciones en Estados Unidos y Europa, figura la denuncia de las masacres cometidas contra los pueblos indígenas como uno de los argumentos centrales para movilizar la solidaridad internacional. Tales denuncias se formalizaron jurídicamente ante tribunales guatemaltecos y extranjeros, y empujaron al sistema de justicia universal e internacional a nuevos terrenos.

De este modo, en el 2013, dicha situación culminó cuando, el crear un primer precedente en la historia mundial, un exjefe de Estado fue condenado por genocidio en su propio país. Este impacto internacional de los enfrentamientos políticos sobre la historia en Guatemala se desarrolló dentro del mismo proceso de paz y estuvo condicionado por el activismo de las organizaciones de víctimas y derechos humanos. También fue un proceso particularmente transnacional que se ve reflejado, por ejemplo, en los entrenamientos de antropólogos forenses en toda América Latina por equipos argentinos; el cual es uno de los casos más conocidos de un alto nivel de colaboración, influencia mutua e intercambio de experiencias y datos entre crecientes comunidades epistémicas en los llamados estudios de posconflicto. ${ }^{3}$

La misma CEH se aprecia como un modelo exitoso dentro del campo de las comisiones de la verdad y de la justicia transnacional; el libro clásico de Priscilla Hayner sobre las comisiones de Verdad, Verdades innombrables, la menciona como una de las cinco comisiones más relevantes en la historia (Hayner, 2008). La historia intelectual de la misma $\mathrm{CEH}$ es otro instante de un múltiple entrecruzamiento en las guerras y paz de Centroamérica. Su constitución y misión formal fue resultado, entre otros factores, de la experiencia crítica del Ejército salvadoreño con la Comisión de la Verdad de Guatemala. La composición reflejó dos de los sectores más afectados de esa nación -la población indígena (comisionada Otilia Lux de Cotí), la clase media ladina centro-democrático (comisionado Alfredo Balsells Tojo) - y la comunidad internacional (el presidente de la comisión y especialista alemán de derecho internacional, Christian Tomuschat).

Tomuschat representa una compleja mezcla de experiencias históricas que a través de su propio proceso de enlazamiento internacional y transnacional, durante la segunda mitad del siglo XX, ha venido preparando el entorno al cual emergió la CEH: el Holocausto Nazi y la memoria transnacional de la persecución antisemita, los crímenes del colonialismo y las atrocidades cometidas en tiempos poscoloniales de la Guerra Fría. El cargo de genocidio se establece como un argumento importante 
en la lucha discursiva anticolonial desde los años sesenta -a partir del Tribunal Russell, del Tribunal Permanente de los Pueblos y otros (Huhle, 2005)- y en Guatemala llega a constituir un elemento importante de la lucha por la hegemonía mnemónica. La genealogía del Holocausto-Vietnam-Guatemala se puede reconstruir a través de los argumentos históricos y jurídicos en los discursos de estas décadas (Molden, 2010; Molden, 2015). Desde esta perspectiva analítica, la historia centroamericana parece ser un ambiente condensado de entrecruzamientos entre actores revolucionarios y antiimperialistas, entre anticomunistas y contrarrevolucionarios, tanto en términos de la historia como de la memoria. De hecho, de cierto modo y contra toda intuición, la historia y la memoria constituyen sus respectivas bases materiales en procesos bidireccionales de objetivación e historización.

\section{A manera de conclusión}

Esta combinación de recorridos generales y acercamientos particulares a constelaciones de la historia intelectual de los grandes antagonismos centroamericanos, especialmente de Guatemala, pretende servir como pantalla de proyección para un mapa diacrónico de entrecruzamientos. Sobre este mapa, actores individuales e institucionales se mueven, se encuentran y se enfrentan a través de fronteras nacionales y regionales. En sus colaboraciones y confrontaciones reflejan relaciones de fuerzas ideológicas y tradiciones intelectuales tanto endógenas como externas, e influyen unos sobre los otros.

Según la demanda epistemológica de la historia cruzada, se quiere identificar una manifestación específica centroamericana que se distinga dentro de los muchos vectores de intercambio que se han indicado aquí, se podría evocar el movimiento neozapatista en Chiapas. De cierta manera en el Ejército Zapatista de Liberación Nacional (EZLN) influye una triada de elementos: el pensamiento y la lucha indígena centroamericana reorganizada desde las grandes movilizaciones de los años setenta, las tradiciones guerrilleras del guevarismo y de la lucha popular prolongada y la doctrina social católica de la liberación. Sin embargo, en el territorio de Chiapas estas se transformaron, a su vez, en una de las influencias más importantes de las llamadas nuevas organizaciones sociales y su discurso transnacional-global crítico de las actuales determinantes de la globalización (Iglesias Turrión, 2004; Le Bot, 2009; Rabasa, 2010).

En su movilización contra las implicaciones del neoliberalismo del Tratado de Libre Comercio de América del Norte (NAFTA, por sus siglas en inglés) -seguido, por supuesto, por los tratados del CAFTA en Centroamérica-, el neozapatismo encarna los elementos centrales de la historia transnacional de los grandes antagonismos centroamericanos en la historia global del siglo XX. No resulta inesperado que el nuevo discurso de seguridad internacional (con enfoque al "terrorismo" en vez del "comunismo"), también identifique los movimientos indígenas de Centroamérica, de Chiapas y de los países andinos como "amenaza a la seguridad 
regional" (Le Bot, 2009: 283), mientras nuevas propuestas revolucionarios regionales deploran que "la balcanización de Centroamérica es una garantía de dominio para el imperialismo y la burguesía" (Fernández et al., 2009: 74).

Así, ante el desafío de este nuevo imperialismo, lo que empezó como una revuelta contra el Gobierno mexicano pronto asumió un discurso muchísimo más amplio. Las experiencias entrelazadas heredadas de las confrontaciones centroamericanas se rearticularon en una amalgama posmoderna que reemplazó la tesis inicial de la liberación nacional con un modelo universal y un proyecto revolucionario "intergaláctico" (EZLN, 1996). De tal modo, la tan prominente posición neozapatista también puede ser vista como producto de la historia cruzada de las guerras centroamericanas, como impronta dejada en un imaginario histórico global. Lo que Arias (2013) observó desde una perspectiva estadounidense se puede confirmar desde la historia intelectual global cruzada: “Centro América no está contenida en una pequeña colección de naciones-estado por allá sino, cada vez más, por acá" (14). Este "acá", en paráfrasis, sería todo sitio, todo lieu de mémoire croisée, donde se pueda identificar los hilos centroamericanos en el tejido de la historia global.

\section{Nota}

1 La retórica de la Fundación Contra el Terrorismo como institución representante del sector más reaccionario del Ejército en el ámbito de las políticas simbólicas, especialmente los discursos sobre la memoria, constituye otro entrecruzamiento más reciente entre Guatemala, Centroamérica y el mundo pos-Guerra Fría. Mientras los mismos grupos -indígenas campesinos organizados- y los mismos temas -reforma agraria, ocupación de tierras- se identifican como adversarios, el término universal para denunciar, criminalizar y externalizar a estos actores y sus prácticas político-sociales ya no es "comunista" sino "terrorista" (véase Molden, 2015). Esta visión de una "difusión del terrorismo" desde América Latina también se encuentra en los discursos conservadores de la Europa oriental poscomunista. En el resumen de una conferencia organizada en 2015 por el infame Instituto Nacional de la Memoria polaco se aclamó, "Las redes del terrorismo de guerra fría se expandieron por todo el globo más allá de las fronteras de Latinoamérica, Europa, Medio Oriente y Asia" (Gasztold-Sen, 2014).

2 Encontré argumentos similares en casi todas las entrevistas que hice con el empresariado organizado y el sector militar: Jorge Briz, Lionel Toriello, Carlos Pineda, Carlos Moreira, Julio Balconi, Mario Mérida. Véase Molden, 2014 y Molden, 2015.

Véanse, aparte de la sistematización llevada a cabo por el Centro Internacional para la Justicia Transnacional (ICTJ por sus siglas en inglés) y otras instancias, por ejemplo los documentos desarrollados durante la intensa cooperación transnacional de antropólogos forenses: Destaca el "II Congreso Mundial de Trabajo Psicosocial en Desaparición Forzada, Procesos de Exhumaciones, Justicia y Verdad" (Bogotá, Colombia, abril 2010), donde también se llegó al "Consenso Mundial principios y normas mínimas sobre trabajo psicosocial en procesos búsqueda e investigaciones forenses para casos de desapariciones forzadas, ejecuciones arbitrarias o extrajudiciales". En lo que concierne de impactos centroamericanos (véase la multitud y diversidad de organizaciones participando en el proceso) vale la pena mencionar que esta iniciativa de sistematización de experiencias a nivel global nació desde Guatemala. 


\section{Bibliografía}

Acuña, Víctor Hugo. Centroamérica: Filibusteros, estados, imperios y memorias. Costa Rica: Editorial Costa Rica, 2014.

Allison, Michael E. y Alberto Martin Álvarez. “Los vínculos revolucionarios centroamericanos: La Unidad Revolucionaria Nacional Guatemalteca". Presentación en el XVII Congreso Internacional de AHILA, Berlín, 9-13 de septiembre de 2014.

Arias, Arturo. "Centroamericanidades: Imaginative Reformulation and New Configurations of Central Americanness". Studies in 20 $0^{\text {th }} \mathcal{E} 21^{\text {st }}$ Century Literature. 37/2 (2013): 11-26.

Armony, Ariel C. La Argentina, los Estados Unidos y la cruzada anticomunista en América Central, 1977-1984. Quilmes: Universidad Nacional de Quilmes, 1999.

. "Transnacionalizando la 'guerra sucia': Argentina en Centroamérica". Espejos de la guerra fría: México, América Central y el Caribe. Coord. Daniela Spenser. México D.F.: SRE/ CIESAS, 2004. 319-348.

Arellano, Jorge Eduardo. "Sócrates Sandino fiel a su hermano hasta la muerte". El Nuevo Diario, Nicaragua. Web. 20 feb de 2010. <http://www.elnuevodiario.com.ni/especiales/68742>

Argueta Villalta, Víctor Emanuel. "Comentarios sobre el juicio Gerardi". La voz del veterano militar. Boletín. 32/IV (2002): 9-11.

AVEMILGUA. Guatemala: Testimonio de una agresión. Guatemala: AVEMILGUA, 1998.

Barrios Celada, Héctor. "Entrevista”. Siglo XXI. 23 de febrero de 1999: 6.

Bethell, Leslie y Ian Roxborough. "Conclusion". Latin America between the Second World War and the Cold War, 1944-1948. Coord. Leslie Bethell y Ian Roxborough. Cambridge: Cambridge University Press, 1992. 328-341.

Bloom, Joshua y Waldo E. Martin, Jr. Black Against Empire. The History and Politics of the Black Panther Party. Berkeley: University of California Press, 2013.

Colussi, Marcelo y Rodrigo Vélez-Guevariando. "Historia de la revolución inconclusa. Entrevista al MIR-EPR de Chile". Web. 7 diciembre de 2014. <http://avancso.codigosur.net/article/historia-de-la-revolucion-inconclusa-entrevista-al/>

Crain, David A. "Guatemalan Revolutionaries and Havana's Ideological Offensive of 19661968". Journal of Interamerican Studies and World Affairs. 17/2 (1975): 175-205.

Cribb, Robert. "Genocide in Indonesia, 1965-1966". Journal of Genocide Research. 3 (2001): 219-39.

Duffet, John, ed. Against the Crime of Silence: Proceedings of the International War Crimes Tribunal (Stockholm, Copenhagen). New York: Simon and Schuster, 1970.

Easter, David. "Keep the Indonesian pot boiling: Western covert intervention in Indonesia, October 1965-March 1966". Cold War History. 5 (2005): 55-73.

EZLN. Invitación-convocatoria al encuentro Intercontinental por la Humanidad y contra el Neoliberalismo, México: EZLN, 1996. Web. Consultado el 9 de mayo de 2015. <http:// palabra.ezln.org.mx/comunicados/1996/1996_06_09.htm>

Falla, Ricardo. Quiché Rebelde. Guatemala: Editorial Universitaria, 1978. Masacres de la finca San Francisco, Huehuetenango, Guatemala. Copenhague: IWGIA, 1983.

Fernández, Javier y Jhon Vega. “Elementos de un programa para la revolución centroamericana". Marxismo Vivo 21 (2009): 73-82.

Fernández, Orlando. Turcios Lima. La Habana: Tricontinental, 1970. 
Fraga, Alfonso. “La OSPAAAL: nuevas convergencias en este siglo". La Jiribilla. 11-18 de marzo de 2011, dossier especial en ocasión del 45 aniversario de la OSPAAAL. Web. 7 de diciembre de 2014. <http://www.lajiribilla.cu/2011/n514_03/514_02.html>

Fundación Contra el Terrorismo. “Quién es Ricardo Falla Sánchez?" Guatemala: FCT, 2013a. Web. 7 de diciembre de 2014. <https://www.facebook.com/ FundacionContraElTerrorismoGuatemala/posts/181754335349137>

Fundación Contra el Terrorismo. Farsa del Genocidio en Guatemala: Conspiración Marxista desde la Iglesia Católica. Guatemala: FCT, 2013.

Gasztold-Sen, Przemyslaw. "In the Shadow of the Cold War. Domestic and International Terrorism in the Former Communist Countries". Anuncio de conferencia. Institute of National Remembrance, Varsovia (8-9 de octubre de 2015). H-Soz-Kult 2 de diciembre de 2014. Web. 7 de diciembre de 2014. <http://www.hsozkult.de/hfn/event/id/termine-26588>

González Bermejo, Ernesto. Entrevista con Carlos Fonseca. Revista Barricada (1979). Web. 7 de diciembre de 2014. <http://librepenicmoncjose.blogspot.fr/ 2009_12_12_archive.html>

Grandin, Greg y Gilbert Joseph, comp. A Century of Revolution. Insurgent and Counterinsurgent Violence During Latin America's Long Cold War. Durham and London: Duke University Press, 2010.

Grandin, Greg. Panzós: La última masacre colonial - Latinoamérica en la Guerra Fría. Guatemala: AVANCSO, 2007.

Hayner, Priscilla. Unspeakable Truths. Transitional Justice and the Challange of Truth Commissions. New York: Routledge, 2011.

Herring, George. "'A Good Stout Effort.' John Foster Dulles and the Indochina Crisis, 1954". John Foster Dulles and the Diplomacy of the Cold War. Coord. Richard Immerman. Princeton: Princeton University Press, 1990. 213-234.

Hobsbawm, Eric. The Age of Extremes: The Short Twentieth Century, 1914-1991. London: Michael Joseph, 1994.

Huhle, Rainer. “De Nuremberg a La Haya. Los crímenes de derechos humanos ante la justicia. Problemas, avances y perspectivas a los 60 años del Tribunal Militar Internacional de Nuremberg". Análisis político (Bogotá). 55 (2005): 20-38.

Iglesia Guatemalteca en el Exilio. La alegría y esperanza del pueblo ante la proclama unitaria de las organizaciones revolucionarias. Comunicado. Managua: IGE, 1982.

Iglesias Turrión, Pablo. “Los indios que invadieron Europa. La influencia del E.Z.L.N. en las formas de acción colectiva de los movimientos globales. Los tute bianche". Ponencia presentada en el X Encuentro de Latinoamericanistas Españoles. Salamanca (13 y 14 de mayo de 2004). Web. 7 de diciembre 2014. <http://www.sindominio.net/ pablo/ papers_propios/Los_Indios_que_invadieron_Europa.pdf $>$

Junta de Coordinación Revolucionaria. “Junta de Coordinación Revolucionaria: orígenes y perspectivas", En: Che Guevara (Revista de la JCR). 2 (1975): 3-4. Web. 7 de diciembre de 2014. <http://www.cedema.org/ver.php?id=92>

Kohan, Néstor. "Pensamiento Crítico y el debate por las ciencias sociales en el seno de la Revolución Cubana". Crítica y teoría en el pensamiento social latinoamericano. Coord. Bettina Levy. Buenos Aires: CLACSO, 2006. 389-437.

Le Bot, Yvon. La guerra en tierras mayas. Comunidad, violencia y modernidad en Guatemala (19701992). México: Fondo de Cultura Económica, 1997. 
Le Bot, Yvon. La grande révolte indienne. Paris: Robert Laffant, 2009.

Löwy, Michael. El Marxismo en América Latina: antología, desde 1909 hasta nuestros días. Santiago de Chile: LOM Editores, 2007.

Ludec, Nathalie. "Voces del exilio guatemalteco desde la ciudad de México". Amérique Latine Histoire et Mémoire. Les Cahiers ALHIM. 2 (2001). Web. 7 de diciembre de 2014. <http:// alhim.revues.org/599>

Marchesi, Aldo. "Geografías de la protesta armada: nueva izquierda y latinoamericanismo en el cono sur. El ejemplo de la Junta de Coordinación Revolucionaria". Sociohistórica. 25 (2009): 41-72.

Martorell, Francisco. Operación Cóndor: el vuelo de la muerte. Santiago de Chile: LOM, 1999.

Mayer, David. “Trotzige Tropen - Kämpferische Klio. Zu marxistisch inspirierten Geschichtsdebatten in Lateinamerika in den ,langen 1960er' Jahren in transnationaler Perspektive". Tesis Doctoral. Universidad de Viena, 2011.

Mcsherry, Patrice. Los estados depredadores: la Operación Cóndor y la guerra encubierta en América Latina. Montevideo: Banda Oriental, 2009.

Molden, Berthold. "Vietnam, the New Left and the Holocaust: How the Cold War changed discourse on genocide". Memory in a Global Age. Coord. Aleida Assmann y Sebastian Conrad. Basingstoke: Palgrave Macmillan. 2010. 79-96.

. Politicas sobre la historia en Guatemala. Historiografía, justicia de posguerra y resarcimiento (1996-2005). Guatemala: AVANCSO, 2014.

"The Reconciliation Trap: Genocide and the Power Relations of Historical Memory in Guatemala". Journal for Genocide Research (por publicarse 2015).

Murga, Hugo, "La misión imposible de Monseñor Quezada Toruño". La voz del veterano militar. Boletin. 31/III (2001): 9.

ODHAG. Guatemala: Nunca más! Informe del Proyecto Recuperación de la Memoria Histórica (REMHI). Guatemala: ODHAG, 1998.

Oikión Solano, Verónica, Eduardo Rey Tristán, y Martín López Ávalos, Comp. El Estudio de las Luchas Revolucionarias en América Latina (1959-1996): estado de la cuestión. Zamora: El Colegio de Michoacán, 2014.

Pablo VI. Evangelii Nuntiandi. Exhortación apostólica. Roma: Paulinas Ediciones, 1975. Web. el 7 de diciembre de 2014. <http://www.vatican.va/holy_father/paul_vi/apost_exhortations/documents/hf_p-vi_exh_19751208_evangelii-nuntiandi_sp.html>

Rabasa, José. Without History. Subaltern Studies, the Zapatista Insurgency, and the Specter of History. Pittsburgh: Pittsburgh University Press, 2010.

Rabe, Stephen. "Dulles, Latin America, and Cold War Anticommunism". John Foster Dulles and the Diplomacy of the Cold War. Coord. Richard Immerman. Princeton: Princeton University Press, 1990. 159-188.

Real Sociedad Económica de Amantes de la Patria de Guatemala. Estatutos. Guatemala, 1796.

Regalado, Roberto, Comp. Insurgencias, diálogos y negociaciones. Centroamérica, Chiapas y Colombia. México: Ocean Sur, 2013.

Rodríguez, Besenia. “De la Esclavitud Yanqui a la Libertad Cubana. U.S. Black Radicals, the Cuban Revolution, and the Formation of a Tricontinental Ideology". Radical History Review 92 (2005): 67-87.

Rojas Núñez, Luis. De la rebelión popular a la sublevación imaginada. Antecedentes de la historia politica y militar del Partido Comunista de Chile y del FPMR, 1973-1990. Santiago de Chile: LOM, 2011. 
Roniger, Luis. Transnational Politics in Central America. Gainesville: University of Florida Press, 2013.

Rosada Granados, Héctor. El lado oculto de las negociaciones de paz. Guatemala: Fundación Friedich Ebert, 1998.

Sawchuk, Dana. "The Catholic Church in the Nicaraguan Revolution: A Gramscian Analysis". Sociology of Religion 58/1 (1997): 39-51.

Segunda Conferencia General del Episcopado Latinoamericano. "La pobreza de la Iglesia". Documentos finales de Medellín. Bogotá: CELAM, 1968.

Taracena, Arturo. "Les fondateurs du Collectif". Solidarité Guatemala 200 (2012): 3-5. Web. 7 de diciembre de $2014<\mathrm{http}: / /$ collectifguatemala.org/Les-fondateurs-du-Collectif-Arturo>

Van Dongen, Luc, Stéphanie Roulin y Giles Scott-Smith, comp. Transnational Anti-Communism and the Cold War: Agents, Activities, and Networks. Basingstoke: Macmillan, 2014.

Werner, Michael y Benedicte Zimmermann. “Beyond comparison: Histoire croisée and the challenge of reflexivity". History.

Berthold Molden. Austriaco, historiador, doctor de la Universidad de Viena. Fue profesor invitado en la University of Chicago, la University of New Orleans y la Université Sorbonne Nouvelle Paris 3. En 2014 publicó Politcas sobre la historia en Guatemala. Historiografía, justicia de posguerra y resarcimiento, 1996-2005. Su enfoque de investigación es la historia intelectual de la Guerra Fría y de la descolonización desde la perspectiva de la historia global. Actualmente trabaja sobre la biografía del historiador Friedrich Katz.

Contacto: berthold.molden@univie.ac.at 
